\title{
Analisis Pertukaran Waktu dan Biaya Menggunakan Metode Time Cost Trade Off (TCTO) pada Proyek Pembangunan Perumahan di PT. $X$
}

\author{
Nailul Izzah \\ Program Studi Teknik Industri \\ Sekolah Tinggi Teknik Qomaruddin Gresik \\ nailul322@gmail.com
}

\begin{abstract}
ABSTRAK
Pada pembangunan proyek perumahan, perencanaan dibutuhkan untuk memperhitungkan berbagai variabel pekerjaan yang menyangkut sumber daya yang terbatas seperti waktu dan biaya. Tujuan dari penelitian ini adalah mendeskripsikan aktivitas jaringan kerja yang optimal dengan metode Critical Path Method (CPM), perencananaan kelayakan yang optimal dengan metode Program Evaluation and Review Technique (PERT), dan mendeskripsikan waktu dan biaya proyek yang efisien dengan metode Time Cost Trade Off (TCTO) pada proses pembangunan perumahan. Jalur kritis dari penerapan metode critical path method (CPM) dimulai dari pekerjaan persiapan $(A)$ sampai pekerjaan pagar $(A B)$, tetapi ada satu yang tidak termasuk pada jalur kritis yaitu pekerjaan plafond $(\mathrm{H})$. Pekerjaan tersebut memiliki nilai slack 25, artinya kegiatan tersebut memiliki kelonggaran waktu pengerjaan selama 25 hari. Dari penerapan metode program evaluation and review technique (PERT), proyek perumahan dapat diselesaikan lebih cepat dari kurun waktu normal selama 555 hari dengan waktu yang diharapkan 547 hari dengan peluang $64,8 \%$. Sedangkan dari penerapan metode time cost trade off (TCTO), efisiensi waktu pengerjaan proyek dengan penambahan pekerja adalah $5,76 \%$ dengan selisih percepatan 32 hari kerja dan efisiensi biayanya adalah $0,156 \%$ dengan biaya optimal sebesar Rp. 6.753.245.793

Kata kunci: Critical Path Method (CPM), Program Evaluation and Review Technique (PERT), Time Cost Trade Off (TCTO).
\end{abstract}

\section{Time Exchange Analysis and Cost Using Time Cost Trade Off (TCTO)} Method in Housing Development Projects in PT. X

\section{ABSTRACT}

In the construction of housing projects, planning is needed to account for the various work variables involving limited resources such as time and cost order to achieve the stated objectives and achieve the desired results. The purpose of this research is to describe optimal network activity from the application of Critical Path Method (CPM) method, to describe optimal feasibility planning from applying of Program Evaluation and Review Technique (PERT) method, and to describe time and cost of efficient project from application of Time method Cost Trade Off (TCTO) on the housing development process. The critical path from the application of the method of critical path method (CPM) starts from the preparatory work $(A)$ to the fence work $(A B)$, but there is one that is not included in the critical path ie the ceiling work $(H)$. The work has a slack value of 25 , meaning that the activity has a working time clearance for 25 days. From the implementation of the evaluation and review technique (PERT) program method, the housing project can be completed faster than the normal time period of 555 days with the expected time 547 days with a chance of $64.8 \%$. While from the time cost trade off (TCTO) method, the time efficiency of project work with the addition of worker is $5.76 \%$ with the acceleration difference of 32 working days and the cost efficiency is $0.156 \%$ with the optimum cost of Rp.6.753.245.793.

Keywords: Critical Path Method (CPM), Program Evaluation and Review Technique (PERT), Time Cost Trade Off (TCTO). 


\section{PENDAHULUAN}

Waktu dan biaya sangat berpengaruh terhadap keberhasilan dan kegagalan suatu proyek. Tolak ukur keberhasilan suatu proyek biasanya dilihat dari waktu penyelesaian yang singkat dengan biaya yang minimal tanpa melupakan mutu dan kualitas hasil dari pekerjaan. Metode pertukaran waktu dan biaya (time cost trade off) adalah suatu metode yang dapat digunakan untuk mempercepat waktu pelaksanaan proyek dan menganalisis pengaruh waktu yang dapat dipersingkat dengan penambahan biaya terhadap kegiatan yang bisa dipercepat kurun waktu pelaksanaannya sehingga dapat diketahui percepatan yang paling maksimum dan biaya yang paling minimum.

Ardika dkk (2014), melakukan analisis konsep nilai hasil dengan mencari nilai EAC dan EAS untuk mengetahui waktu dan biaya yang dibutuhkan pada akhir proyek dengan menggunakan metode Time Cost Trade Off. Dengan dilakukannya penambahan jam kerja terjadi percepatan waktu dalam pengerjaannya. Akan tetapi terjadi penambahan biaya langsung dan variable cost mengalami penurunan.

\section{Critical Path Method}

Critical path method CPM) adalah sebuah metode dalam manajemen proyek yang digunakan untuk melakukan penjadwalan, mengatur, dan mengkoordinasi bagian- bagian pekerjaan yang ada didalam suatu proyek. Dari data yang telah diperoleh yaitu berbagai aktivitas yang dikerjakan pada suatu proses, hubungan antar aktivitas yang satu dengan yang lain dan durasi masing- masing aktivitas maka dapat dibuat suatu jaringan kerja untuk mengetahui kapan aktivitas itu dapat dilakukan dan dapat diselesaikan. Hal ini dapat diketahui dengan melakukan perhitungan maju dan perhitungan mundur.

\section{Program Evaluation and Review Technique (PERT)}

Program evaluation and review technique (PERT) adalah suatu metode yang bertujuan untuk mengurangi adanya penundaan, maupun gangguan produksi, serta mengkoordinasi berbagai bagian suatu pekerjaan secara menyeluruh dan mempercepat selesainya proyek. Dengan kata lain, program evaluation and review technique(PERT) membantu kita dalam penyelesaian pekerjaan dan untuk mengetahui kemungkinan mencapai target jadwal penyelesaian.

\section{Time Cost Trade Off (TCTO)}

Time cost trade off(TCTO) atau pertukaran waktu dan biaya merupakan suatu cara yang digunakan untuk mempercepat waktu pelaksanaan pada proyek dengan cara melakukan pengujian dari semua kegiatan dalam suatu proyek yang dipusatkan pada kegiatan yang berada pada jalur kritis yang disengaja dan sistematis. Dalam penelitian ini telah dibatasi bahwa kegiatan percepatan durasi proyek akan dilakukan dengan penambahan jam kerja (jam lembur) dan penambahan tenaga kerja. 
a. Produktivitas Kerja Lembur

Secara umum, produktivitas merupakan perbandingan antara output dan input. Dibidang konstruksi, output dapat dilihat dari kuantitas pekerjaan yang telah dilakukan. Sedangkan inputnya merupakan jumlah sumber daya yang dipergunakan. Formula untuk menghitung produktivitas kerja lembur sebagai berikut:

a. Produktivitas harian

$$
=\frac{\text { Volume }}{\text { Durasi normal }}
$$

b. Produktivitas tiap jam

$=\frac{\text { Produktivitas harian }}{9 \mathrm{Jam}}$

c. Produktifitas harian sesudah crash

$=$ (jam kerja perhari $x$ produktivitas tiap jam) + (lama penambahan jam kerja lembur $x$ koefisien penurunan produktivitas akibat penambahan jam jam kerja (lembur) produktivitas tiap jam)

b. Penambahan Pekerja

Untuk menyelenggarakan proyek, salah satu sumber daya yang menjadi faktor penentu keberhasilannya adalah tenaga kerja.Formula sebagai berikut:

a. Normal ongkos perhari $=$ Produktifitas harian $\mathrm{x}$ harga satuan upah pekerja

b. Normal ongkos pekerja perjam

$=$ Produktifitas perjam $\mathrm{x}$ harga satuan upah pekerja

c. Biaya lembur pekerja $1,5 \times$ upah sejam normal untuk penambahan jam kerja

d. Crash cost pekerja perhari $=$ (jam kerja perhari $\mathrm{x}$ normal cost pekerja) + (jumlah penambahan jam kerja lembur $x$ biaya lembur perjam) e. Cost slope

$=\frac{\text { Crash cost }- \text { Normal cost }}{\text { Durasi normal-Durasi } \text { crash }}$

\section{METODE PENELITIAN}

Rancangan Penelitian

Pada penelitian ini menggunakan berbagai data angka berupa data mengenai waktu dan biaya yang digunakan selama proses pembangunan proyek berlangsung, sehingga penelitian ini disebut penelitian kuantitatif.

\section{Data Penelitian}

Data yang dipergunakan dalam penelitian ini adalah sebagai berikut:

a. Aktivitas kegiatan proses pengerjaan perumahan.

b. Jadwal pelaksanaan proyek.

c. Hubungan ketergantungan antar kegiatan.

d. Waktu (durasi).

e. Rencana Anggaran Biaya (RAB).

f. Perkiraan kebutuhan tenaga kerja.

\section{Sumber Data Penelitian}

a. Data Primer

Data primer merupakan data yang diperoleh secara langsung dari objek penelitian yang dilakukan melalui pengamatan langsung, wawancara, dan metode lain.

b. Data Sekunder

Data sekunder ini bersumber dari data- data dan record yang dimiliki oleh pihak perusahaan.

\section{Teknik Analisis Data Penelitian}

a. Tahap Pertama

Pada tahap pertama dilakukan studi lapangan dan studi literatur, setelah itu dilakukan identifikasi masalah. Setelah dilakukan identifikasi masalah kemudian disusun rumusan masalah, tujuan penelitian, 
manfaat penelitian, dan dilakukan pengumpulan data.

b. Tahap Kedua

Tahap kedua merupakan proses pengolahan data. Dalam proses pengolahan data terdapat tiga tahapan yaitu perhitungan menggunakan metode Critical path method(CPM), program evaluation and review technique(PERT), dan time cost trade off(TCTO).

c. Tahap Ketiga

Tahap ketiga dilakukan pembuatan kesimpulan dan saran.

\section{Hasil dan Pembahasan \\ Critical Path Method (CPM)}

Waktu yang dibutuhkan untuk menyelesaikan pembangunan perumahan adalah sebesar 555 hari dengan lintasan kritis yang terbentuk adalah A, B, C, D, E, F, G, I, J, K, L, $\mathrm{M}, \mathrm{N}, \mathrm{O}, \mathrm{P}, \mathrm{Q}, \mathrm{R}, \mathrm{S}, \mathrm{T}, \mathrm{U}, \mathrm{V}, \mathrm{W}, \mathrm{X}, \mathrm{Y}$, $Z$, $A A, A B$. Pada kegiatan $H$ tidak termasuk dalam lintasan kritis karena memiliki slack 25. Hal itu berarti kegiatan tersebut memiliki durasi kelonggaran waktu sebesar 25 hari.

\section{Program Evaluation and Review Technique (PERT)}

Waktu penyelesaian yang diharapkan adalah 547,67. Untuk lebih lengkapnya dapat dilakukan perhitungan sebagai berikut:
a. $\mathrm{TE}=547,67$
b. $\mathrm{V}(\mathrm{TE})=355,55$
c. $S$ $=\sqrt{V(T E)}=19$
d. Kemungkinan mencapai target (Td), untuk proyek pembangunan perumahan yang ditargetkan selesai dalam waktu 555 hari, maka :

$\mathrm{Z}=\frac{T d-T E}{S}=\frac{555-547,67}{19}=0,3857$

Dengan nilai $Z=0,3857$ diperoleh angka probabilitas sebesar $64,8 \%$ (dilihat dalam tabel distribusi normal). Hal ini berarti kemungkinan proyek selesai pada target yaitu 555 hari dengan waktu yang diharapkan 547 hari.

\section{Time Cost Trade Off (TCTO)}

Dalam perencanaan penambahan jam kerja lembur memakai 9 jam kerja normal dan 1 jam istirahat (08.00- 17.00), sedangkan kerja lembur dilakukan setelah waktu kerja normal (18.0022.00).

Dibawah ini merupakan salah satu perhitungan dalam menentukan jam kerja (lembur):
a. Pekerjaan persiapan

Volume $=989 \mathrm{~m}^{2}$

Durasi normal $=7$ hari

Durasi normal $=63$ jam

Produktivitas jam normal $=\frac{\text { volume }}{\text { durasi normal }}$

$=15,6984 \mathrm{~m}^{2} / \mathrm{jam}$

$\frac{\text { Maksimal }}{989 \text { crashing }}=5$ hari

Diambil asumsi $=2$ hari

Durasi percepatan $=5$ hari

Durasi percepatan $=45$ jam

Produktivitas jam dipercepat

$$
=\frac{\text { volume }}{\text { durasi dipercepat }}
$$

$=21,9778 \mathrm{~m}^{2} / \mathrm{jam}$

Waktu lembur perhari =
$\frac{21,9778-15,6984}{15,6984} \times 9$ jam $\times 80 \%$
$=2$ jam 
Untuk tambahan waktu lembur dilakukan 4 hari pertama selama proyek berlangsung.

Tambahan waktu lembur

$$
=2 \mathrm{jam} / \text { hari } \times 4 \text { hari }=8 \mathrm{jam}
$$

Biaya lembur

- $\quad$ Pekerja $=($ Rp. $12.500 \times 1,5)+$ $($ Rp. $12.500 \times 2)=$ Rp. 43.750

- $\quad$ Tukang $=($ Rp.15.000 $\times 1,5)+$ (Rp. $15.000 \times 2)=$ Rp. 52.500

- $\quad$ Pengawas $=(R p .17 .500 \times 1,5$ )$+(\operatorname{Rp} .17 .500 \times 2)=R p$. 61.250

Upah lembur

- Pekerja $=10 \times 4 \times$ Rp. 43.750 $=$ Rp. 1.750 .000

- $\quad$ Tukang $=5 \times 4 \times$ Rp. 52.500

$$
=\text { Rp. } 1.050 .000
$$

- $\quad$ Pengawas $=1 \times 4 \times$ Rp. 61.250

Total $=$ Rp. 3.045.000

$$
=\text { Rp. } 245.000
$$

Biaya normal= Rp. 125.226.785

Biaya percepatan

$=$ Rp. $125.226 .785+R p$.

3.045 .000

$=$ Rp. 128.271 .785

Slope biaya perhari

$=\frac{\text { Biaya percepatan-Biaya normal }}{\text { Durasi normal-Durasi percepatan }}$

$=\frac{\text { Rp.128.271.785 - Rp.125.226.785 }}{7-5}$

$=\mathrm{Rp} .1 .525 .500$

Slope biaya setelah crashing

$=$ Rp. $1.525 .500 \times 2$

$=$ Rp. 3.045 .000

Dari penambahan jam kerja (lembur) diperoleh total biaya proyek dengan durasi atau umur proyek yang optimal yaitu 523 hari kerja dengan total biaya proyek yang optimum sebesar Rp. 6.762.540.793 dengan presentase efisiensi waktu dan biaya proyek adalah sebagai berikut:

1. Efisiensi waktu proyek

$=555 \mathrm{Hk}-523 \mathrm{Hk}$

$=32$ Hari Atau

$=\frac{555-523}{555} \times 100 \%=5,76 \%$

2. Efisiensi biaya proyek $=$ Rp.6.763.839.127Rp.6.762.540.793

$$
\begin{aligned}
& =\text { Rp. } 1.298 \cdot 334 \text { Atau } \\
& =\frac{\text { Rp.6.763.839.127-Rp.6.762.540.793 }}{\text { Rp.6.762.540.793 }} x \\
& 100 \% \quad=0,019 \%
\end{aligned}
$$

Penambahan Pekerja

a. Pekerjaan persiapan

Volume $=989 \mathrm{~m}^{2}$

Durasi normal $=7$ hari

Kapasitas tenaga kerja per $\mathrm{m}^{3}$ adalah:

Pekerja $=0,074$ orang $/$ hari

$$
=\text { Rp. } 100.000
$$

Tukang $=0,034$ orang $/$ hari $=$ Rp. 120.000

Pengawas $=0,035$ orang $/$ hari $=$ Rp. 140.000

Kapasitas pekerja

$$
=\frac{1}{0,074}=13,5135
$$

Jumlah pekerja

$$
=\frac{989}{14,7059 \times 7 \text { hari }}=10,455143
$$

Jadi upah pekerja

$=10$ orang $\times$ Rp. 100.000

$=\mathrm{Rp} .1 .000 .000$

Kapasitas tukang

$$
=\frac{1}{0,034}=29,4118
$$

Jumlah tukang

$=\frac{989}{29,4118 \times 7 \text { hari }}$

$$
=4,80371
$$

Jadi upah tukang

$=5$ orang $x$ Rp. 120.000

$=$ Rp. 600.000

Kapasitas pengawas $=\frac{1}{0,068 / 0,035}$ $=0,5147059$

Jumlah pengawas

$=0,5147059 \times 1$ orang

$=0,5147059$

Jadi upah pengawas

$=1$ orang $\times$ Rp. 140.000

$=$ Rp. 140.000

Upah tenaga kerja selama durasi normal pekerjaan adalah:

$=($ Rp. $1.000 .000+R p .600 .000+$ Rp. 140.000) x 7 hari

= Rp. 12.180 .000

Pekerjaan ini akan dipercepat dengan durasi percepatan 2 hari, 
adapun perhitungannya adalah sebagai berikut:

Kondisi percepatan

Durasi $=5$ hari

Volume $=989$

Perhitungan biaya tenaga kerja adalah:

Kapasitas pekerja $=\frac{1}{0,074}=13,5135$

Jumlah pekerja $=\frac{989}{13,5135 \times 5 \text { hari }}=15$

orang

Jadi upah pekerja

$$
\begin{aligned}
& =15 \text { orang } x \text { Rp. } 1.000 \\
& =\text { Rp. } 1.500 .000
\end{aligned}
$$

Kapasitas tukang

$$
=\frac{1}{0,034}=29,411765
$$

Jumlah tukang

$$
=\frac{989}{29,411765 \times 5 \text { hari }}=7 \text { orang }
$$

Jadi upah tukang

$=7$ orang $x$ Rp. 120.000

$$
=\text { Rp. } 840.000
$$

Kapasitas pengawas

$$
=\frac{1}{0,068 / 0,035}=0,5147059
$$

Jumlah pengawas

$$
=0,5147059 \times 1 \text { orang }
$$

$=0,5147059$

$=1$ orang

Jadi upah pengawas

$=1$ orang $\times$ Rp. 140.000

$=$ Rp. 140.000

Upah tenaga kerja selama durasi pekerjaan dipercepat adalah: $=($ Rp. $1.500 .000+$ Rp.840.000+ Rp. 140.000) x 5 hari $=$ Rp. 12.400 .000

Slope biaya akibat percepatan adalah:

Slope biaya

Biaya dipersingkat-Biaya normal

$=$ Waktu normal-waktu dipersingkat

$=\frac{\text { Rp.12.400.000 -Rp.12.180.000 }}{7-5}$

$=$ Rp. 110.000 per hari
Slope biaya untuk percepatan 2 hari $=$ Rp. $110.000 \times 2$ hari

$=$ Rp. 220.000 .

Total biaya proyek dengan durasi proyek yang optimal yaitu pada durasi 523 hari kerja dengan total biaya proyek yang optimum sebesar Rp. 6.753.245.793. Dengan efisiensi waktu dan biaya proyek adalah sebagai berikut:

1. Efisiensi waktu proyek $=555 \mathrm{Hk}-523 \mathrm{Hk}=32$ Hari. Atau $\frac{555-523}{555} \quad$ x $100 \%$ $=5,76 \%$

2. Efisiensi biaya proyek $=$ Rp.6.763.839.127Rp.6.753.245.793 $=$ Rp. 10.593.334

Atau $\frac{\text { Rp.6.763.839.127 - Rp.6.753.245.793 }}{\text { Rp.6.753.245.793 }}$ x $100 \%$ $=0,156 \%$

Waktu optimal yang didapatkan dan yang dapat digunakan adalah dari penambahan pekerja yaitu selama 523 hari dengan biaya yang paling optimal yaitu sebesar $\mathrm{Rp}$. 6.753.245.793. Dikarenakan penambahan pekerja lebih optimal, maka digunakan hasil dari penambahan pekerja yang dibandingkan dengan data dari perusahaan.

Untuk efisiensi waktu pengerjaan proyek adalah 5,76\% dengan selisih percepatan 32 hari kerja. Biaya durasi normal dari 555 hari kerja adalah sebesar Rp. 6.763.839.127. Sedangkan dengan menggunakan percepatan diperoleh 523 hari kerja dengan biaya optimal adalah sebesar Rp. 6.753.245.793. 
Untuk efisiensi biaya dalam pengerjaan proyek adalah $0,156 \%$ dengan selisish biaya normal dengan percepatan adalah Rp. 10.559.334.

\section{SIMPULAN}

Berdasarkan data yang telah diperoleh dan dari perhitungan yang telah dilakukan, diperoleh kesimpulan sebagai berikut:

a. Pada proses pembangunan proyek pembangunan perumahan di PT $X$, aktivitas kegiatan yang berada dijalur kritis adalah pekerjaan dengan simbol (A), (B), (C), (D), (E), (F), (G), (I), (J), (K), (L), (M), (N), (O), (P), (Q), (R), (S), (T), (U), (V), $(\mathrm{W}),(\mathrm{X}),(\mathrm{Y}),(\mathrm{Z}),(\mathrm{AA}),(\mathrm{AB})$. Tetapi ada satu kegiatan pengerjaan pada proyek pembangunan ini yang tidak termasuk pada jalur kritis yaitu pekerjaan dengan simbol $(\mathrm{H})$. Pekerjaan tersebut memiliki nilai slack 25, artinya kegiatan

DAFTAR PUSTAKA

Husen, Abrar. (2010). Manajemen Proyek. Yogyakarta: Andi.

Husnan, Suad dan Suwarsono Muhammad. (2000). Studi Kelayakan Industri. Yogyakarta: Unit Penerbit dan Percetakan.

Maranresy, Petrus, Bonny F. Sompie, Pingkan Pratasis. (2015). Sistem Pengendalian Waktu pada Pekerjaan Konstruksi Jalan Raya dengan Menggunakan Metode Cpm. Manado: Fakultas Teknik Jurusan Teknik Sipil Universitas Sam Ratulangi Manado, Jurnal Sipil Statik Vol. 3 No. 1. tersebut memiliki waktu kelonggaran waktu pengerjaan selama 25 hari.

b. Proyek pembangunan perumahan di PT $X$ dapat diselesaikan lebih cepat dari kurun waktu normal selama 555 hari dengan waktu yang diharapkan 547 hari dengan peluang $64,8 \%$.

c. Efisiensi waktu pengerjaan proyek adalah 5,76\% dengan selisih percepatan 32 hari kerja. Biaya durasi normal dari 555 hari kerja adalah sebesar $\mathrm{Rp}$. 6.763.839.127. Sedangkan dengan menggunakan percepatan diperoleh 523 hari kerja dengan biaya optimal adalah sebesar Rp. 6.753.245.793. Untuk efisiensi biaya dalam pengerjaan proyek adalah 0,156 \% dengan selisish biaya normal dengan percepatan adalah Rp. 10.559.334.

Messah, Yunita Afliana, Lazry Hellen Paula Lona, dan Dantje A. T. Sina. (2013). Pengendalian Waktu dan Biaya Pekerjaan Konstruksi Sebagai Dampak dari Perubahan Desain Studi Kasus Embung Irigasi Oenaem, Kecamatan Biboki Selatan, Kabupaten Timor Tengah Utara. Kupang: Jurusan Tenik Sipil Fakultas Sains dan Teknik Universitas Nusa CendanaKupang, Jurnal Teknil Sipil. Vol. II No. 2.

Priyo, Mandiyo dan Muhammad Raa'uf Aulia. (2015). Aplikasi Metode Time Cost Trade Off pada Proyek Konstruksi Studi Kasus 
Proyek Pembangunan Gedung Indonesia. Jurnal Ilmiah Semesta Teknika. Vol. 18 No. $130-43$.

Santosa, Budi. 2008. Manajemen Proyek Konsep Dan Implementasi. Surabaya: Graha IImu.

Sandjaja, B dan Albertus Heriyanto. (2006). Panduan Penelitian. Jakarta: Prestasi Pustakaraya.

Satiawan, Budi. (2004). Memanfaatkan Primavera Project Planner Dalam Mengelola Proyek Konstruksi. Yogyakarta: Andi.

Stiawan, Bagus Budi. 2012, Analisis Pertukaran Waktu dan Biaya dengan Metode Time Cost Trade Off (TCTO) pada Proyek Pembangunan Gedung Di Jakarta. Jakarta: Jurusan Teknik Sipil
Universitas Muhammadiyah Jakarta, Jurnal Konstruksia. Vol. 4 No. 1 hal. 1. http: //jurnal. umj. ac. id/ index. php? journal= konstruksia\& page $=$ article $\&$ op...[diakses dan diunduh pada Senin, 19 Desember 2016, 13: 15].

Wiratmani, Elfitria dan Galih Prawitasari. 2013, Penerapan Metode Jalur Kritis dalam Penyusunan Jadwal Pelaksanaan Proyek Pembangunan Fasilitas Rumah Karyawan. Program Studi Teknik Industri Fakultas Teknik Matematika dan IPA. http:// journal. Ippmunindra. ac. id/ index. php/ Faktor_Exactal article/ download/233/ 219 diakses dan diunduh pada 4 Desember 2016, 20: 09]. 